\title{
Change in Fitness and the Relation to Change in Cognition and Neuropsychiatric Symptoms After Aerobic Exercise in Patients with Mild Alzheimer's Disease
}

\author{
Nanna A. Sobol ${ }^{\mathrm{a}, *}$, Christian Have Dall ${ }^{\mathrm{a}, \mathrm{b}}$, Peter Høgh ${ }^{\mathrm{c}}$, Kristine Hoffmann ${ }^{\mathrm{d}}$, \\ Kristian Steen Frederiksen ${ }^{\mathrm{d}}$, Asmus Vogel ${ }^{\mathrm{d}}$, Volkert Siersma ${ }^{\mathrm{e}}$, Gunhild Waldemar ${ }^{\mathrm{d}}$, \\ Steen G. Hasselbalch ${ }^{\mathrm{d}}$ and Nina Beyer ${ }^{\mathrm{a}}$ \\ ${ }^{a}$ Department of Physical and Occupational Therapy and Institute of Sports Medicine, \\ Bispebjerg Hospital, University of Copenhagen, Denmark \\ ${ }^{\mathrm{b}}$ Department of Cardiology, Bispebjerg Hospital, University of Copenhagen, Denmark \\ ${ }^{\mathrm{c} Z}$ Zealand University Hospital, Regional Dementia Research Centre, Department of Neurology, \\ Denmark and Department of Clinical Medicine, University of Copenhagen, Copenhagen, Denmark \\ ${ }^{\mathrm{d}}$ Danish Dementia Research Center, Department of Neurology, Rigshospitalet, Copenhagen \\ University Hospital, Denmark \\ ${ }^{\mathrm{e}}$ The Research Unit for General Practice and Section of General Practice, Department of Public Health, \\ University of Copenhagen, Copenhagen, Denmark
}

Accepted 16 June 2018

\begin{abstract}
.
Background: Physical activity has the potential to improve physical function in patients with Alzheimer's disease (AD) and may contribute to modify disease processes and cognitive function.

Objective: The aim of this study was to investigate 1) the effect of moderate-high-intensity aerobic exercise on cardiorespiratory fitness, i.e., peak oxygen uptake $\left(\mathrm{VO}_{2 \text { peak }}\right)$ determined by direct breath-by-breath cardiopulmonary exercise test, and 2) the association between changes in $\mathrm{VO}_{2 \text { peak }}$ and changes in cognition and neuropsychiatric symptoms in patients with mild AD.

Methods: The study is based on secondary outcome analyses from the large single-blinded multi-center study ADEX (Preserving Cognition, Quality of Life, Physical Health and Functional Ability in Alzheimer's Disease: The Effect of Physical Exercise). A preselected sub-group of 55 participants (age 52-83 years), 29 from the intervention group (IG) and 26 from the control group (CG), was included. IG performed 16 weeks of supervised moderate-to-high intensity aerobic exercise. Assessments of $\mathrm{VO}_{2 \text { peak }}$, mental speed and attention (Symbol Digit Modalities Test, SDMT), and neuropsychiatric symptoms (Neuropsychiatric Inventory, NPI) were performed at baseline and at 16 weeks.

Result: $\mathrm{VO}_{2 \text { peak }}$ increased $13 \%$ in the IG and a between-group difference in mean change $(3.92 \mathrm{ml} / \mathrm{kg} / \mathrm{min}, 95 \% \mathrm{CI} 6.34-1.51$, $p=0.003$ ) was present in favor of the IG. Combined data from IG and CG showed positive associations between changes in $\mathrm{VO}_{2 \text { peak }}$ and changes in NPI $(\mathrm{Rho}=-0.41, p=0.042)$ and changes in SDMT $(\mathrm{Rho}=0.36, p=0.010)$, respectively.

Conclusion: Aerobic exercise improves $\mathrm{VO}_{2 \text { peak }}$ in community-dwelling patients with mild AD. Furthermore, changes in $\mathrm{VO}_{2 \text { peak }}$ appear to be associated to changes in cognition and neuropsychiatric symptoms.
\end{abstract}

Keywords: Alzheimer's disease, aerobic exercise, cardiorespiratory fitness, cognitive function, neuropsychiatric symptoms

\footnotetext{
*Correspondence to: Nanna Aue Sobol, PhD, PT, Department of Physical and Occupational Therapy - Copenhagen, Bispebjerg and Frederiksberg Hospitals, University of Copenhagen,
}

Bispebjerg Bakke 23, DK-2400 Copenhagen NV, Denmark. E-mail: naauso@gmail.com. 


\section{INTRODUCTION}

The benefits of physical activity on physical function and cognitive performance in patients with Alzheimer's disease (AD) are receiving increased attention due to the lack of a disease modifying medical treatment in AD. Studies have shown that physical activity has the potential to improve physical function and helps to maintain activities of daily living in patients with dementia [1-3]. In addition, both animal studies and studies in humans suggest that physical activity may have a role in modifying the disease process and maintaining cognitive function in $\mathrm{AD}$ [4]. In patients with AD, a link between cardiorespiratory fitness (determined by peak oxygen uptake, $\mathrm{VO}_{2 \text { peak }}$ ) and cognition has been suggested, and low $\mathrm{VO}_{2 \text { peak }}$ appears to be associated with brain atrophy in patients with mild $\mathrm{AD}$ [5-7]. However, the association between $\mathrm{VO}_{2 \text { peak }}$ and cognition in patients with $\mathrm{AD}$ is still unclear. Based on trials that were highly heterogeneous in terms of dementia type and severity, and exercise mode, two meta-analyses concluded that it is not yet established if physical exercise has a positive effect on cognitive function in patients with dementia [1,8]. A third meta-analysis of 18 RCTs and 802 patients [8] concluded that physical activity interventions has a positive overall effect on cognitive function, and that the effect is driven by interventions that included aerobic exercises independent of the type of dementia [9].

The multi-center study ADEX (Preserving Cognition, Quality of Life, Physical Health and Functional Ability in Alzheimer's Disease: the Effect of Physical Exercise) included 200 community-dwelling persons with mild AD and showed that 16 weeks of moderateto-high intensity aerobic exercise had a positive effect on $\mathrm{VO}_{2 \text { peak }}$ (estimated by the Astrand test) and neuropsychiatric symptoms (using the 12-item Neuropsychiatric Inventory, NPI) [10, 11]. While the primary outcome Symbol Digit Modalities Test (SDMT), a test of mental speed and attention, did not improve in the intention-to-treat population, the per protocol analyses showed that results in SDMT were preserved in participants with high exercise attendance and high training intensity compared to those in the control group [10]. This suggests that a dose-response relation between aerobic exercise and cognition may be present. However, in the main study we were not able to detect whether the effects on SDMT and NPI were mediated by the exercise intervention itself or other factors including a generally higher physical activity level, the social interaction between participants and/or the interaction with health professionals.

Only one of the ADEX-centers had the gold standard equipment for measuring peak oxygen uptake $\left(\mathrm{VO}_{2 \text { peak }}\right)$, which was the reason why the Astrand test $[12,13]$ was chosen to estimate $\mathrm{VO}_{2 \text { peak }}$ in the main study. This test is relatively inexpensive, simple, easy to implement, appropriate for assessing change over time, and can be carried out in persons with mild-moderate dementia. However, the formula for calculating $\mathrm{VO}_{2 \text { peak }}$ uses the age predicted maximal heart rate ( $\mathrm{HR}=220$-age), an estimate which is subject to some uncertainty [14]. In addition, valid test results cannot be obtained in persons who use betablockers or other medications that reduce the heart rate, because either the target $\mathrm{HR}$ cannot be achieved or the $\mathrm{VO}_{2 \text { peak }}$ is overestimated.

In patients with $\mathrm{AD}$, only few studies have measured $\mathrm{VO}_{2 \text { peak }}$ by direct breath-by-breath cardiopulmonary exercise test (CPET) [5-7, 15-17], which is the gold standard for assessing $\mathrm{VO}_{2 \text { peak }}$. Furthermore, to our knowledge no studies have investigated whether exercise can improve $\mathrm{VO}_{2 \text { peak }}$ measured by CPET in patients with mild AD. Based on secondary outcome analyses from a subset of the participants in the ADEX study, the aim of this study was to investigate 1) the effect of moderate-to-high intensity aerobic exercise on $\mathrm{VO}_{2 \text { peak }}$ in patients with mild AD using CPET, and 2) the association between changes in $\mathrm{VO}_{2 \text { peak }}$ and changes in cognition and neuropsychiatric symptoms.

\section{MATERIALS AND METHODS}

This study included data from a subset of participants in the large randomized controlled trial ADEX, a single-blinded multicenter RCT, which involved 8 Danish memory clinics and enrolled 200 participants from January 2012 to June 2014. Only 3 of the 8 memory clinics had the equipment for advanced cardiopulmonary exercise testing and expertise in testing. The 55 participants from these three memory clinics in the Metropolitan area (Danish Dementia Research Center, Rigshospitalet; Regional Dementia Research Center, Roskilde Hospital; and Memory Clinic, Glostrup Hospital) were offered to participate in the sub-study. 55 of 66 (29 from the intervention group and 26 from the control group) agreed to participate in the sub-study and after the assessments in the main study they completed a test of maximal oxygen uptake $\left(\mathrm{VO}_{2 \text { peak }}\right)$. 
The study adhered to the Helsinki declaration and was approved by The Danish National Committee on Biomedical Research Ethics (H-3-2011-128) and informed consent was obtained from each participant. ClinicalTrials.gov no.: NCT01681602.

\section{Participants and study procedures}

Inclusion criteria were: a diagnosis of $\mathrm{AD}$ according to the NINCDS-ADRDA criteria [18]; age 50-90 years; a score of 20 or above on the Mini-Mental State Examination (MMSE); and having contact more than once monthly to a caregiver who accepted to take part in the study. Use of anti-dementia or mood stabilizing medication was permitted if the doses had been stable for at least three months preceding the enrolment.

Exclusion criteria were: unstable cardiac disease; any musculoskeletal problems, joint problems and neurological diseases that contraindicated aerobic exercise; participation in moderate to high intensity exercise twice or more weekly. The complete list of all inclusion and exclusion criteria has been published in a protocol paper [19].

Patients who agreed to participate and fulfilled the inclusion criteria completed the baseline assessments and were subsequently randomized in groups of 4-10 participants to an intervention group (IG) or a control group (CG) at each of the contributing memory clinics. The randomization was done using a computerized random-number generator in favor of the exercise program if an odd number of participants were included.

\section{Intervention}

The participants in the IG exercised $1 \mathrm{~h} 3$ times weekly for 16 weeks in groups of 2-5 participants supervised by an experienced physiotherapist. In week $1-4$, the priority was on strength training of the lower extremity muscles (twice weekly) and introduction to aerobic exercise (once weekly). The following 12 weeks comprised 10 min of warm up followed by 3 times $10 \mathrm{~min}$ of moderate-tohigh intensity aerobic exercise with small breaks of 2-5 min in between. The exercise was conducted on an ergometer bicycle, cross trainer, or treadmill and the target intensity was $70-80 \%$ of maximal hearth rate (HR, i.e., 220 minus the person's age). The average HR was monitored during the aerobic exercises $(3 \times 10 \mathrm{~min}$ of exercise plus the pauses, in total 34-40 $\mathrm{min}$ ) and documented in a training logbook. For each participant, the exercise intensity was estimated as: average HR of all exercise sessions/maximal HR (\%). To ensure that the planned training intensity was reached the Borg Scale of Perceived Exertion was used as a supplement [20]. The total number of attended exercise sessions/total number of offered exercise sessions (\%) was used to determine the attendance rate of each participant. Low adherence did not lead to exclusion.

The participants in the CG received usual care during the 16 weeks of the exercise intervention.

\section{Assessments}

$\mathrm{VO}_{2 \text { peak }}$ was measured at baseline and after the 16week intervention by a specialized physiotherapist at Bispebjerg Hospital who had extensive expertise in testing cardiac patients. Cognitive tests and neuropsychiatric scales were administered by raters at the memory clinics. All assessors were blinded to the allocation of the participants.

\section{$\mathrm{VO}_{2 \text { peak }}$}

CPET was performed using a graded cycle ergometer (Monarch) with a pedaling frequency of $>60$ RPM and increment increasing load to exhaustion, and a completed test in 6-12 min [21]. The test was performed with a mask for measurement of peak oxygen uptake by indirect calorimetry and expired gases were collected online and analyzed with a metabolic measurement system (Jaeger, Master Screen CPX vers.5.21, Cardinal Health, Germany). Maximal effort was determined by the respiratory exchange ratio (RER), currently the best non-invasive indicator of exercise effort and a secondary criterion for having attained maximal oxygen uptake [22].

$\mathrm{VO}_{2 \text { peak }}$ was measured at termination of the test, caused by either cardiovascular exhaustion or onset of leg fatigue requiring termination of the test. Variables selected for this paper are $\mathrm{VO}_{2 \text { peak }}(\mathrm{ml} / \mathrm{kg} / \mathrm{min})$, absolute $\mathrm{VO}_{2 \text { peak }}(\mathrm{ml} / \mathrm{min}$ ), RER (ratio) and maximal HR (beats/min).

CPET was self-terminated by the subjects when they claimed that they had achieved maximal effort. However, we considered maximal or nearly maximal effort to be achieved if the RER was $\geq 1.05$ [23].

\section{Cognitive tests and neuropsychiatric rating}

The Symbol Digit Modalities Test (SDMT) [24]: The primary outcome measure in the ADEX study was the SDMT, which assesses mental speed and attention. Participants are asked to decode lines of symbols for $120 \mathrm{~s}$ using a number to symbol key. The 
test score is defined as the number of correct answers. A higher test score indicates a better performance.

The 12-item Neuropsychiatric Inventory (NPI) [25]: Based on interviews with caregivers the NPI assesses symptoms and behavior common in patients with dementia. This includes hallucinations, agitation, depression, anxiety, apathy, etc., which is retrospectively assessed for the previous 4 weeks. The score range is $0-144$ with higher ratings indicating worse symptoms and behavior.

\section{Descriptive variables}

Sex, age, comorbidities, general cognitive impairment (MMSE), co-habitation, and physical activity.

\section{Statistical analyses}

To assess the differences in baseline characteristics between the IG and the CG, Fisher's exact test was used for categorical data, and Wilcoxon's signed rank test for continuous data. The differences in outcome changes from baseline to the 16-week follow-up between the two randomization-groups were analyzed in linear regression models. The method of generalized estimating equations (GEE) was used to account for the longitudinal data; indicator variables were used to adjust for heterogeneity between clinics and training groups. Data on the outcomes at followup were weighted by the inverse of the probability of still being in the study; estimated in a logistic regression model with the patient's baseline characteristics and the observed outcome at baseline as covariates. The associations between changes in SDMT, NPI, and $\mathrm{VO}_{2 \text { peak }}$ were assessed by Spearman's rank correlation coefficient, rho. SAS 9.4 was used for all analyses. The level of significance was $p \leq 0.05$.

\section{RESULTS}

Of the 55 participants enrolled into the sub study, 52 completed the baseline test and 49 completed the test at follow-up (Fig. 1).

The median age was 69 years (range 52-83), which is similar to the median age in the whole ADEX patient group [11]. There were no significant between-group differences in any of the baseline characteristics shown in Table 1.

Exercise attendance rate (mean(SD)) was $85.2 \%$ (16.8\%) and exercise intensity $79.6 \%$ (10.6\%) of maximal heart rate for participants not using betablockers in the intervention group $(n=24,92 \%)$.
Training was safe with no serious adverse events related to the exercise intervention [11].

The test of $\mathrm{VO}_{2 \text { peak }}$ was not performed in three of the 55 included participants due to use of pacemaker $(n=1)$, a recently sprained ankle $(n=1)$, and knee pain $(n=1)$. RER of $>1.05$ was achieved in $37(76 \%)$ out of 49 participants who completed the baseline and follow-up tests.

\section{Effect of the 16 weeks exercise intervention on $\mathrm{VO}_{2 \text { peak }}$}

We found a $13 \%$ increase in $\mathrm{VO}_{2 \text { peak }}$ $(2.9 \mathrm{ml} / \mathrm{kg} / \mathrm{min})$ in IG following the intervention period and a retained $\mathrm{VO}_{2 \text { peak }}$ in $\mathrm{CG}(-0.8 \mathrm{ml} / \mathrm{kg} / \mathrm{min})$ (Table 2). The between-group differences in mean change from baseline was in favor of the IG following the intervention period for both $\mathrm{VO}_{2 \text { peak }}(p=0.003)$ and absolute $\mathrm{VO}_{2 \text { peak }}(p=0.001)$ (Table 2). There was no between-group difference in changes in body weight $(p=0.446)$ (Table 2).

Excluding participants with an RER $\leq 1.05$ from the analyses did not change the results (Table 3 ).

\section{Associations}

The relationship between changes over 16 weeks in $\mathrm{VO}_{2 \text { peak }}$ and the selected measures of cognition and neuropsychiatric symptoms were examined for participants with complete data sets. We found significant positive associations between changes in $\mathrm{VO}_{2 \text { peak }}$ and NPI $(\mathrm{Rho}=-0.41, p=0.042)$ and between changes in $\mathrm{VO}_{2 \text { peak }}$ and SDMT (Rho $=0.36$, $p=0.010$ ) (Figs. 2 and 3). Separate analyses of data from each group showed that there was a positive association between $\mathrm{VO}_{2 \text { peak }}$ and SDMT (rho $=0.74$, $p<0.0001)$ in the control group but not in the intervention group ( $\mathrm{rho}=0.23 ; p=0.26$ ); and there was no correlation between NPI and $\mathrm{VO}_{2 \text { peak }}$ in any of the groups.

\section{DISCUSSION}

To our knowledge, this study is the first randomized controlled trial to find a significant effect of an exercise intervention on $\mathrm{VO}_{2 \text { peak }}(\mathrm{ml} / \mathrm{kg} / \mathrm{min})$ when using CPET in patients with mild AD. When pooling data from the IG and the CG our results show that there is a positive association between changes in $\mathrm{VO}_{2 \text { peak }}$ and changes in cognitive test results and ratings of neuropsychiatric symptoms in patients with mild AD. 


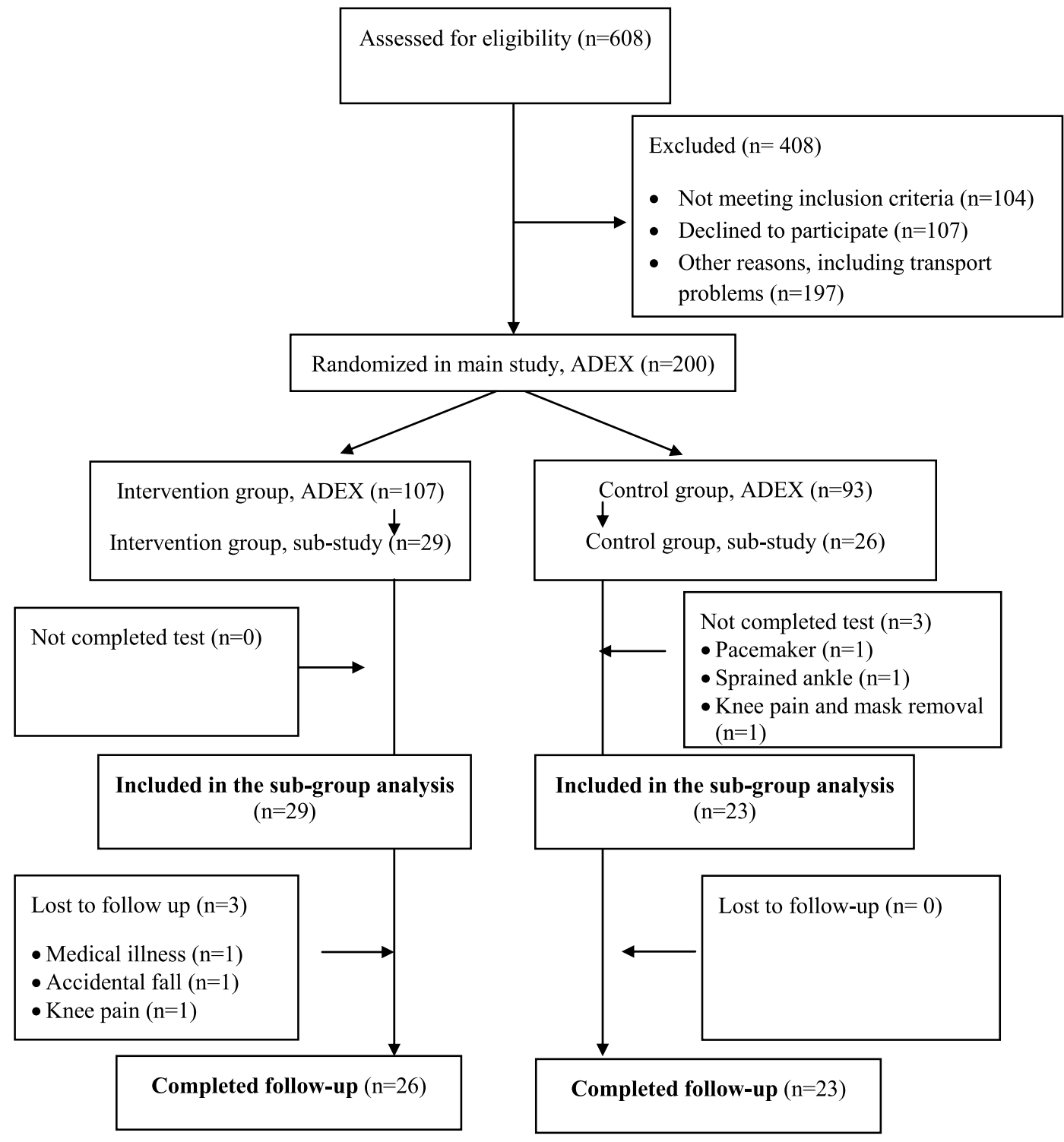

Fig. 1. Flowchart of the sub-group study in ADEX.

$\mathrm{VO}_{2 \text { peak }}$ can be improved by exercise in patients with mild cognitive impairment (MCI) [26] but the feasibility of improving $\mathrm{VO}_{2 \text { peak }}$ in patients with $\mathrm{AD}$ has so far not been established. In older healthy adults $\mathrm{VO}_{2 \text { peak }}$ is related to overall physical function [27], and in patients with early stage $\mathrm{AD}$ a correlation between $\mathrm{VO}_{2 \text { peak }}$ and physical functional performance, e.g., 50-foot walk and chair rise, has been reported [17]. Because high physical capacity helps maintain activities of daily living in patients with dementia [1-3], improving $\mathrm{VO}_{2 \text { peak }}$ may have important implications for decreasing the risk of dependency in patients with AD. A meta-analysis
[9] suggests that aerobic exercises positively influence cognitive function in patients with dementia, and in line with this we found a correlation between changes in $\mathrm{VO}_{2 \text { peak }}$ and NPI and SDMT, respectively, when we combined the data from the IG and the CG. The physiological mechanism behind our findings is unknown. However, an association between $\mathrm{VO}_{2 \text { peak }}$, memory composite score and hippocampal volume in patients with MCI and AD has been reported [28].

Results from previous studies suggest that it is feasible to measure and detect changes in $\mathrm{VO}_{2 \text { peak }}$ using CPET in patients with mild AD [7, 16, 28, 29]. Of the 55 participants, only 2 participants were unable 
Table 1

Baseline characteristics

\begin{tabular}{|c|c|c|c|}
\hline & Intervention Group & Control Group & $p$ \\
\hline $\mathrm{n}(\%)$ & $29(53.7)$ & $26(47.3)$ & \\
\hline Sex (male), $n(\%)$ & $14(48.3)$ & $17(65.4)$ & 0.278 \\
\hline Age $(\mathrm{y})$, mean $(S D)$ & $69.2(6.9)$ & $68.9(7.2)$ & 0.854 \\
\hline Caregiver living with patient, $n(\%)$ & $23(79.3)$ & $18(69.2)$ & 0.537 \\
\hline PASE, median (IQR) & $76(60-121)$ & $97(55-143)$ & 0.458 \\
\hline \multicolumn{4}{|l|}{ Comorbidities } \\
\hline Hypertension, $n(\%)$ & $13(44.8)$ & $11(42.3)$ & 0.850 \\
\hline Diabetes, $n(\%)$ & $3(10.3)$ & $2(7.7)$ & 0.733 \\
\hline Hypercholesterolemia, $n(\%)$ & $10(34.5)$ & $8(30.8)$ & 0.770 \\
\hline Stroke, $n(\%)$ & $0(0)$ & $0(0)$ & \\
\hline Acute myocardial infarction, $n(\%)$ & $0(0)$ & $0(0)$ & \\
\hline \multicolumn{4}{|l|}{ Medicine } \\
\hline Hypertension medicines, $n(\%)$ & $13(44.8)$ & $10(61.5)$ & 0.785 \\
\hline Depression medicines, $n(\%)$ & $6(20.7)$ & $5(19.2)$ & 0.893 \\
\hline Alzheimer medicines, $n(\%)$ & $29(100)$ & $23(88.5)$ & 0.100 \\
\hline Betablockers, $n(\%)$ & $2(6.9)$ & $2(7.7)$ & 0.910 \\
\hline \multicolumn{4}{|l|}{ Cognitive performance } \\
\hline MMSE, mean (SD) & $25.1(2.9)$ & $25.5(3.3)$ & 0.607 \\
\hline SDMT, mean (SD) & $35.0(12.3)$ & $28.1(14.6)$ & 0.074 \\
\hline NPI, mean (SD) & $7.9(8.1)$ & $9.2(10.2)$ & 0.607 \\
\hline \multicolumn{4}{|l|}{ Cardiorespiratory fitness, mean (SD) } \\
\hline $\mathrm{VO}_{2 \text { peak }} n=52(\mathrm{ml} / \mathrm{kg} / \mathrm{min})^{*}$ & $21.9(5.9)$ & $25.3(6.9)$ & 0.068 \\
\hline $\mathrm{VO}_{2 \text { peak }} \mathrm{RER} \geq 1.05(\mathrm{ml} / \mathrm{kg} / \mathrm{min})^{*}$ & $23.4(6.0)$ & $26.6(6.6)$ & 0.134 \\
\hline $\mathrm{VO}_{2 \text { peak }}$ absolute $(\mathrm{ml} / \mathrm{min})^{* *}$ & $1,563(448)$ & $1,714(574)$ & 0.297 \\
\hline $\mathrm{VO}_{2 \text { peak }}$ absolute $\mathrm{RER} \geq 1.05,(1 / \mathrm{min})^{* *}$ & $1,636(449)$ & $1,821(559)$ & 0.249 \\
\hline Respiratory exchange ratio (RER) & $1.17(0.14)$ & $1.15(0.14)$ & 0.574 \\
\hline Maximal heart rate (bpm) & $137(24)$ & $140(24)$ & 0.656 \\
\hline
\end{tabular}

MMSE, Mini-Mental State Examination range from 0 (severe impairment) to 30 (no impairment); SDMT, Symbol Digit Modalities Test. Number of correct matches in $120 \mathrm{~s}$ are reported, with a higher score indicating a higher level of mental speed and attention; NPI, Neuropsychiatric Inventory range from 0 to 144, with higher scores indicating increased behavioral and psychological symptoms; PASE, Physical activity scale for the elderly, with higher scores indicating higher levels of habitual physical activity; $\mathrm{VO}_{2 \text { peak }}$, Peak oxygen uptake measured by direct breath-by-breath cardiopulmonary exercise test (CPET); RER, respiratory exchange ratio.

Table 2

Effect of the 16 weeks exercise intervention on $\mathrm{VO}_{2 \text { peak }}$

\begin{tabular}{|c|c|c|c|c|c|c|}
\hline \multirow[b]{2}{*}{ Variables } & \multicolumn{2}{|c|}{ Intervention group $(n=29)$} & \multicolumn{2}{|c|}{ Control group $(n=23)$} & \multicolumn{2}{|c|}{$\begin{array}{l}\text { Between-group differences in } \\
\text { mean change from baseline }\end{array}$} \\
\hline & Baseline & $\begin{array}{l}\text { 16-week } \\
\text { follow-up }\end{array}$ & Baseline & $\begin{array}{l}\text { 16-week } \\
\text { follow-up }\end{array}$ & $\Delta(95 \% \mathrm{CI})$ & $p$ \\
\hline $\mathrm{VO}_{2 \text { peak }}(\mathrm{ml} / \mathrm{kg} / \mathrm{min})$ & $21.9(5.9)$ & $24.8(7.4)$ & $25.9(6.5)$ & $25.1(5.5)$ & $-3.9(-6.3 ;-1.5)$ & 0.003 \\
\hline $\mathrm{VO}_{2 \text { peak }}(\mathrm{ml} / \mathrm{min})$ & $1,563(448)$ & $1,771(578)$ & $1,747(564)$ & $1,635(610)$ & $-330(-489 ;-170)$ & 0.001 \\
\hline RER & $1.17(0.14)$ & $1.13(0.13)$ & $1.16(0.13)$ & $1.14(0.13)$ & $-0.03(-0.06 ; 0.00)$ & 0.087 \\
\hline $\mathrm{HR}_{\max }(\mathrm{bpm})$ & $137(24)$ & $136(25)$ & $142(21)$ & $142(24)$ & $-3.4(-11.3 ; 4.6)$ & 0.402 \\
\hline Body weight (kg) & $72.3(14.9)$ & $72.1(15.9)$ & $67.3(12.0)$ & $68.9(12.5)$ & $-0.6(-2.1 ; 0.9)$ & 0.446 \\
\hline
\end{tabular}

Baseline and 16-week follow-up with unadjusted mean \pm SD and mean outcomes of the Intervention Group compared to mean outcomes in Control Group, beyond the difference already present at baseline, adjusted for clustering within training groups and centers, RER: respiratory exchange ratio, $\mathrm{HR}_{\max }$ : maximal heart rate.

to perform the CPET due to comorbidities not related to $\mathrm{AD}$, and only one person was unable to complete the test due to knee pain. Further, the proportion of participants with an RER $\geq 1.05$ in our study complies with a reliability study $(n=14)$ finding $71 \%$ of patients with mild $A D$ reaching an $R E R \geq 1.05$ and 93\% reaching an RER $>1.0$ in a treadmill exercise test [29]. In that study, an excellent reliability (ICC $=0.92$,
CI 0.78-0.97) was reported, when $\mathrm{VO}_{2 \text { peak }}$ was measured 3 days apart [29]. We chose a cycle ergometer test because all Danes learn to bike at an early age and biking for transportation is very common throughout life. One could also speculate that patients with $\mathrm{AD}$ may feel safer on a cycle ergometer, which is not as challenging with regards to balance as a treadmill, especially for those who have gait impairment, 
Table 3

Effect of the 16 weeks exercise intervention on $\mathrm{VO}_{2 \text { peak }}$ if $\mathrm{RER} \geq 1.05$

\begin{tabular}{|c|c|c|c|c|c|c|}
\hline \multirow[b]{2}{*}{ Variables } & \multicolumn{2}{|c|}{ Intervention group, $n=20$} & \multicolumn{2}{|c|}{ Control group, $n=17$} & \multicolumn{2}{|c|}{$\begin{array}{c}\text { Between-group } \\
\text { differences in mean } \\
\text { change from baseline }\end{array}$} \\
\hline & Baseline & $\begin{array}{c}16 \text {-week } \\
\text { follow-up }\end{array}$ & Baseline & $\begin{array}{c}\text { 16-week } \\
\text { follow-up }\end{array}$ & $\Delta(95 \% \mathrm{CI})$ & $\mathrm{p}$ \\
\hline $\mathrm{VO}_{2 \text { peak }}(\mathrm{ml} / \mathrm{kg} / \mathrm{min})$ & $23.4(6.0)$ & $26.0(7.0)$ & $26.6(6.6)$ & $25.7(6.1)$ & $-4.2(-6.7 ;-1.8)$ & 0.001 \\
\hline $\mathrm{VO}_{2 \text { peak }}(\mathrm{ml} / \mathrm{min})$ & $1,636(449)$ & $1,893(533)$ & $1,821(559)$ & $1,717(650)$ & $-352(-609 ;-94)$ & 0.007 \\
\hline RER & $1.22(0.11)$ & $1.18(0.08)$ & $1.20(0.10)$ & $1.20(0.09)$ & $0.03(-0.02 ; 0.08)$ & 0.258 \\
\hline $\mathrm{HR}_{\max }(\mathrm{bpm})$ & $141(22)$ & $141(23)$ & $146(19)$ & $150(21)$ & $2.7(-6.3 ; 11.5)$ & 0.560 \\
\hline Body weight (kg) & $73.6(15.5)$ & $73.8(15.8)$ & $68.2(12.7)$ & $70.5(10.4)$ & $1.2(-3.1 ; 5.5)$ & 0.583 \\
\hline
\end{tabular}

Baseline and 16-week follow-up with unadjusted means \pm SD and mean outcomes of the Intervention Group compared to mean outcomes in Control Group, beyond the difference already present at baseline, adjusted for clustering within training groups and centers, RER: respiratory exchange ratio, $\mathrm{HR}_{\max }$ : maximal heart rate.

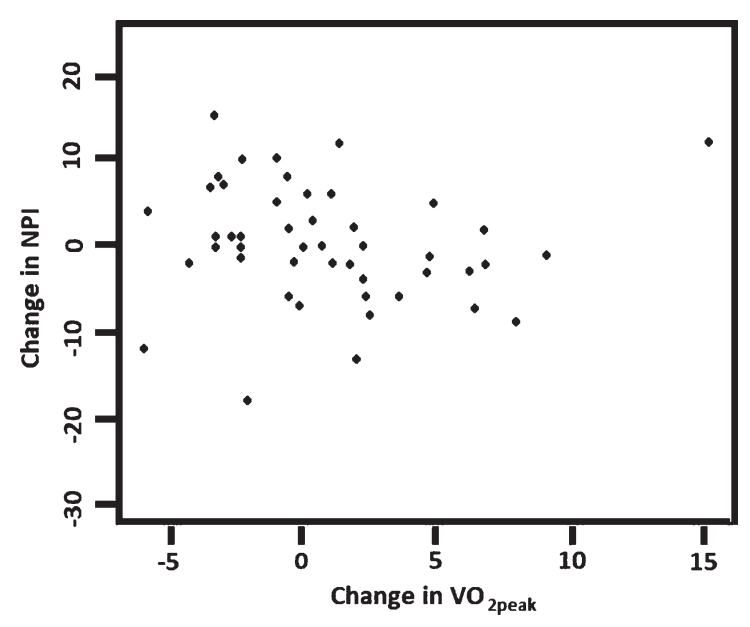

Fig. 2. Correlation between changes in $\mathrm{VO}_{2 \text { peak }}$ and changes in NPI $(n=49)$, Rho $=-0.41, p=0.042$. NPI, Neuropsychiatric Inventory, score range $0-144$, with higher scores indicating increased behavioral and psychological symptoms.

motor coordination complications, and/or are afraid of falling [30].

A general improvement in neuropsychiatric symptoms (NPI) following the exercise intervention was present in the main study, and SDMT improved in participants with the highest exercise dose [10]. Our results showed a positive association between changes in $\mathrm{VO}_{2 \text { peak }}$ and neuropsychiatric symptoms, which suggests a mutual effect of cognition on neuropsychiatric symptoms, and potentially imply a positive effect of exercise training upon $\mathrm{AD}$ cognitive capacity and symptoms.

Although the analyses suggest causal effects, this cannot be ascertained, and furthermore the analyses cannot detect potential mediating effects. Also, in our study, the correlation between cognition/neuropsychiatric symptoms and $\mathrm{VO}_{2 \text { peak }}$ was not straightforward: when correlations were performed

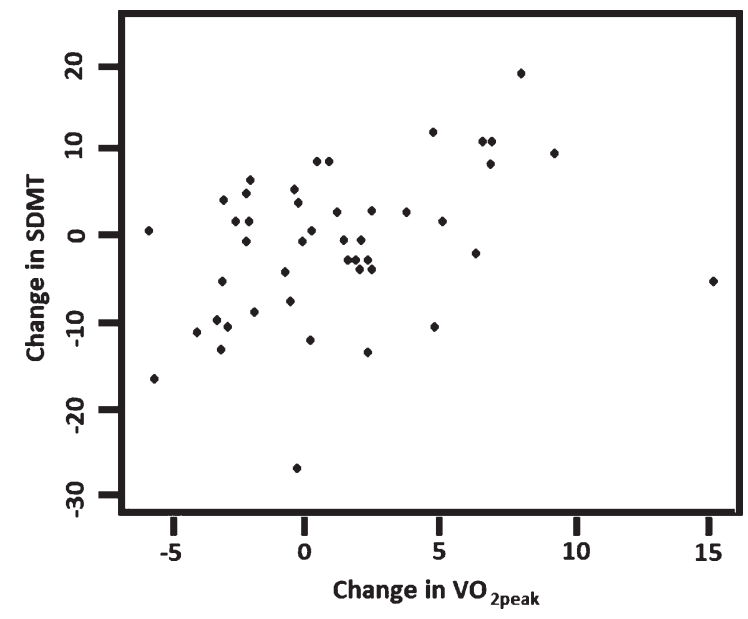

Fig. 3. Correlation between changes in $\mathrm{VO}_{2 \text { peak }}$ and changes in SDMT $(n=47)$, Rho $=0.36, p=0.010$. SDMT, Symbol Digit Modalities Test are the number of correct matches in $120 \mathrm{~s}$, with a higher score indicating a higher level of mental speed and attention.

separately on control group and intervention group, the association was only evident in the control group for SDMT. There could be numerous explanations for this unexpected finding, but obviously, the small sample size makes interpretations difficult. In particular, we cannot exclude that other factors not accounted for may have caused changes in symptoms and fitness in both groups. However, the association is noteworthy and calls for more research into the area.

The link between $\mathrm{VO}_{2 \text { peak }}$ and symptomatology of $\mathrm{AD}$ may in theory be mediated through effects on the pathophysiology associated with AD [4]. Crosssectional studies have found an association between $\mathrm{VO}_{2 \text { peak }}$ and brain atrophy in $\mathrm{AD}[5,6]$, and in a longitudinal study $\mathrm{VO}_{2 \text { peak }}$ was associated with progression of dementia severity and brain atrophy over 2 years in patients with AD [7]. These results suggest that high $\mathrm{VO}_{2 \text { peak }}$ may have an impact on the 
rate of neurodegeneration. A direct effect on specific AD pathology (amyloid- $\beta$ and tau accumulation) is still uncertain [31], although an exercise program similar to ours documented a reduction in tau in cerebrospinal fluid as a result of exercise in older adults with MCI [32]. Multiple other mechanisms that could be induced in the relatively short time interval of 4 months may more likely be involved. These include improved cerebrovascular and endothelial function, reduction in oxidative stress and neuroinflammation, and improved metabolic function, which may contribute to improved neuronal function $[4,33$, 34]. In healthy persons using resting-state functional magnetic resonance imaging, exercise increased the functional connectivity of neural networks [35], but this mechanism has not yet been established in AD. In addition, studies have found exercise associated increases in levels of brain-derived neurothropic factor (BDNF) and insulin-like growth factor 1 (IGF-1) to be important factors behind the possible protective mechanism of physical activity $[4,36]$, but evidence for these pathways is scarce in $\mathrm{AD}$ [31].

In the main effect study $(n=200)$, we did not find any significant association between changes in estimated $\mathrm{VO}_{2 \text { peak }}$ and changes in results in cognitive tests and in neuropsychiatric ratings [11]. One of the reasons for this discrepancy in results could be the aforementioned problem with the Astrand test, a method that is less valid than direct breath-by-breath CPET measurement [12-14].

The strength of our study includes a meticulous design including highly supervised moderate to high aerobic exercise with a high adherence rate and the use of the gold standard CPET measurement of $\mathrm{VO}_{2 \text { peak }}$ in a well characterized group of communitydwelling patients with mild AD. A weakness of the study is that the control group was not offered any social activity. It cannot be excluded that the social interaction in the training group may have had a positive impact on changes in NPI, and that the social interaction in the training group may have contributed to the high adherence rate and thus to the improvement in fitness. Finally, our sample is fairly small and our participants were physically well-functioning [37], which may limit the generalizability of our findings to all patients with mild AD.

\section{Conclusion}

Our study shows that it is possible to improve cardiorespiratory fitness in community-dwelling patients with mild AD. Moreover, the results suggest that this improvement may have a positive effect on mental speed, attention and neuropsychiatric symptoms in patients with mild AD. However, studies are needed to confirm the findings from our study and determine, which mechanisms that may explain potential causal relations between cardiorespiratory fitness and cognition and neuropsychiatric symptoms, respectively.

\section{ACKNOWLEDGMENTS}

The ADEX study is supported by a grant from the Innovation Fund Denmark (j. no.: 10-092814) and this work is supported by the Lundbeck Foundation (grant number FP 73/2012). The Danish Dementia Research Centre is supported by grants from the Danish Ministry of Health (J.no: 2007-12143-112, project 59506/J.no: 0901110, project 34501) and the Danish Health Foundation (J.no.: 2007B004).

Authors' disclosures available online (https: //www.j-alz.com/manuscript-disclosures/18-0253 r2).

\section{REFERENCES}

[1] Forbes D, Forbes SC, Blake CM, Thiessen EJ, Forbes S (2015) Exercise programs for people with dementia. Cochrane Database Syst Rev 4, CD006489.

[2] Blankevoort CG, van Heuvelen MJ, Boersma F, Luning H, de Jong J, Scherder EJ (2010) Review of effects of physical activity on strength, balance, mobility and ADL performance in elderly subjects with dementia. Dement Geriatr Cogn Disord 30, 392-402.

[3] Littbrand H, Stenvall M, Rosendahl E (2011) Applicability and effects of physical exercise on physical and cognitive functions and activities of daily living among people with dementia: A systematic review. Am J Phys Med Rehabil 90, 495-518.

[4] Phillips C, Akif Baktir M, Das D, Lin B, Salehi A (2015) The link between physical activity and cognitive dysfunction in Alzheimer disease. Phys Ther 95, 1046-1060.

[5] Burns JM, Cronk BB, Anderson HS, Donnelly JE, Thomas GP, Harsha A, Brooks WM, Swerdlow RH (2008) Cardiorespiratory fitness and brain atrophy in early Alzheimer disease. Neurology 71, 210-216.

[6] Honea RA, Thomas GP, Harsha A, Anderson HS, Donnelly JE, Brooks WM, Burns JM (2009) Cardiorespiratory fitness and preserved medial temporal lobe volume in Alzheimer disease. Alzheimer Dis Assoc Disord 23, 188-197.

[7] Vidoni ED, Honea RA, Billinger SA, Swerdlow RH, Burns JM (2012) Cardiorespiratory fitness is associated with atrophy in Alzheimer's and aging over 2 years. Neurobiol Aging 33, 1624-1632.

[8] Ohman H, Savikko N, Strandberg TE, Pitkala KH (2014) Effect of physical exercise on cognitive performance in older adults with mild cognitive impairment or dementia: A systematic review. Dement Geriatr Cogn Disord 38, 347-365. 
[9] Groot C, Hooghiemstra AM, Raijmakers PG, van Berckel BN, Scheltens P, Scherder EJ, van der Flier WM, Ossenkoppele R (2016) The effect of physical activity on cognitive function in patients with dementia: A meta-analysis of randomized control trials. Ageing Res Rev 25, 13-23.

[10] Hoffmann K, Sobol NA, Frederiksen KS, Beyer N, Vogel A, Vestergaard K, Brændgaard H, Gottrup H, Lolk A, Wermuth L, Jacobsen S, Laugesen LP, Gergelyffy RG, Høgh P, Bjerregaard E, Andersen BB, Siersma V, Johannsen P, Cotman CW, Waldemar G, Hasselbalch SG (2016) Moderate-to-high intensity physical exercise in patients with Alzheimer's disease: A randomized controlled trial. J Alzheimers Dis 50, 443-453.

[11] Sobol NA, Hoffmann K, Frederiksen KS, Vogel A, Vestergaard K, Braendgaard H, Gottrup H, Lolk A, Wermuth L, Jakobsen S, Laugesen L, Gergelyffy R, Hogh P, Bjerregaard E, Siersma V, Andersen BB, Johannsen P, Waldemar G, Hasselbalch SG, Beyer N (2016) Effect of aerobic exercise on physical performance in patients with Alzheimer's disease. Alzheimers Dement 12, 1207-1215.

[12] Astrand PO, Ryhming I (1954) A nomogram for calculation of aerobic capacity (physical fitness) from pulse rate during sub-maximal work. J Appl Physiol 7, 218-221.

[13] Cink RE, Thomas TR (1981) Validity of the AstrandRyhming nomogram for predicting maximal oxygen intake. Br J Sports Med 15, 182-185.

[14] Robergs RA, Landwehr R (2002) The surprising history of the "HRmax=220-age" equation. $J$ Exerc Physiol Online 5, $1-10$.

[15] Burns JM, Mayo MS, Anderson HS, Smith HJ, Donnelly JE (2008) Cardiorespiratory fitness in early-stage Alzheimer disease. Alzheimer Dis Assoc Disord 22, 39-46.

[16] Billinger SA, Vidoni ED, Honea RA, Burns JM (2011) Cardiorespiratory response to exercise testing in individuals with Alzheimer's disease. Arch Phys Med Rehabil 92, 2000-2005.

[17] Vidoni ED, Billinger SA, Lee C, Hamilton J, Burns JM (2012) The physical performance test predicts aerobic capacity sufficient for independence in early-stage Alzheimer disease. J Geriatr Phys Ther 35, 72-78.

[18] McKhann G, Drachman D, Folstein M, Katzman R, Price D, Stadlan EM (1984) Clinical diagnosis of Alzheimer's disease: Report of the NINCDS-ADRDA Work Group under the auspices of Department of Health and Human Services Task Force on Alzheimer's Disease. Neurology 34, 939-944.

[19] Hoffmann K, Frederiksen KS, Sobol NA, Beyer N, Vogel A, Simonsen AH, Johannsen P, Lolk A, Terkelsen O, Cotman CW, Hasselbalch SG, Waldemar G (2013) Preserving cognition, quality of life, physical health and functional ability in Alzheimer's disease: The effect of physical exercise (ADEX trial): Rationale and design. Neuroepidemiology $\mathbf{4 1}$, 198-207.

[20] Borg G (1970) Perceived exertion as an indicator of somatic stress. Scand J Rehabil Med 2, 92-98.

[21] Fletcher GF, Ades PA, Kligfield P, Arena R, Balady GJ, Bittner VA, Coke LA, Fleg JL, Forman DE, Gerber TC, Gulati M, Madan K, Rhodes J, Thompson PD, Williams MA (2013) Exercise standards for testing and training: A scientific statement from the American Heart Association. Circulation 128, 873-934.

[22] Guazzi M, Adams V, Conraads V, Halle M, Mezzani A, Vanhees L, Arena R, Fletcher GF, Forman DE, Kitzman DW, Lavie CJ, Myers J (2012) EACPR/AHA Scientific
Statement. Clinical recommendations for cardiopulmonary exercise testing data assessment in specific patient populations. Circulation 126, 2261-2274.

[23] Magri D, Corra U, Di Lenarda A, Cattadori G, Maruotti A, Iorio A, Mezzani A, Giannuzzi P, Mantegazza V, Gondoni E, Sinagra G, Piepoli MF, Fiorentini C, Agostoni P (2014) Cardiovascular mortality and chronotropic incompetence in systolic heart failure: The importance of a reappraisal of current cut-off criteria. Eur J Heart Fail 16, 201-209.

[24] Smith A (1982) Symbol Digit Modalities Test (SDMT) Manual (revised). Western Psychological Services, Los Angeles.

[25] Cummings JL, Mega M, Gray K, Rosenberg-Thompson S, Carusi DA, Gornbein J (1994) The Neuropsychiatric Inventory: Comprehensive assessment of psychopathology in dementia. Neurology 44, 2308-2314.

[26] Baker LD, Frank LL, Foster-Schubert K, Green PS, Wilkinson CW, McTiernan A, Plymate SR, Fishel MA, Watson GS, Cholerton BA, Duncan GE, Mehta PD, Craft S (2010) Effects of aerobic exercise on mild cognitive impairment: A controlled trial. Arch Neurol 67, 71-79.

[27] Arnett SW, Laity JH, Agrawal SK, Cress ME (2008) Aerobic reserve and physical functional performance in older adults. Age Ageing 37, 384-389.

[28] Billinger SA, Vidoni ED, Greer CS, Graves RS, Mattlage AE, Burns JM (2014) Cardiopulmonary exercise testing is well tolerated in people with Alzheimer-related cognitive impairment. Arch Phys Med Rehabil 95, 1714-1718.

[29] Anderson HS, Kluding PM, Gajewski BJ, Donnelly JE, Burns JM (2011) Reliability of peak treadmill exercise tests in mild Alzheimer disease. Int J Neurosci 121, 450-456.

[30] Bronas UG, Salisbury D, Kelly K, Leon A, Chow L, Yu F (2017) Determination of aerobic capacity via cycle ergometer exercise testing in Alzheimer's disease. Am J Alzheimers Dis Other Demen 32, 500-508.

[31] Jensen CS, Hasselbalch SG, Waldemar G, Simonsen AH (2015) Biochemical markers of physical exercise on mild cognitive impairment and dementia: Systematic review and perspectives. Front Neurol 6, 187.

[32] Baker LD, Skinner JS, Craft S, Sink KM, Montine T, Hansen A, Wilson VM, Jung Y, Johnston M, Cholerton B, Callaghan M (2015) Aerobic exercise reduces phosphorylated tau protein in cerebrospinal fluid in older adults with mild cognitive impairment. Alzheimers Dementia 11(Suppl), P324.

[33] Intlekofer KA, Cotman CW (2013) Exercise counteracts declining hippocampal function in aging and Alzheimer's disease. Neurobiol Dis 57, 47-55.

[34] Lange-Asschenfeldt C, Kojda G (2008) Alzheimer's disease, cerebrovascular dysfunction and the benefits of exercise: From vessels to neurons. Exp Gerontol 43, 499504.

[35] Rajab AS, Crane DE, Middleton LE, Robertson AD, Hampson M, MacIntosh BJ (2014) A single session of exercise increases connectivity in sensorimotor-related brain networks: A resting-state fMRI study in young healthy adults. Front Hum Neurosci 8, 625.

[36] Bherer L, Erickson KI, Liu-Ambrose T (2013) A review of the effects of physical activity and exercise on cognitive and brain functions in older adults. J Aging Res 2013, 657508.

[37] Sobol NA, Hoffmann K, Vogel A, Lolk A, Gottrup H, Hogh P, Hasselbalch SG, Beyer N (2016) Associations between physical function, dual-task performance and cognition in patients with mild Alzheimer's disease. Aging Ment Health 20, 1139-1146. 